\title{
ESTUDO DA RELAÇÃO HOMEM-NATUREZA NA OBRA DE LUIZ GONZAGA: UMA CONTRIBUIÇÃO À EDUCAÇÃO AMBIENTAL
}

\author{
R. C. C. BENIGNO ${ }^{1 *}$, L. X. COSTA NETO ${ }^{1}$ e M. K. M. CUNHA ${ }^{2}$ \\ Instituto Federal de Educação, Ciência e Tecnologia do Rio Grande de Norte ${ }^{1}$ \\ Universidade do Estado do Rio Grande do Norte ${ }^{2}$ \\ carolbenigno_2@hotmail.com**
}

Submetido 31/10/2017 - Aceito 21/11/2017

DOI: $10.15628 /$ holos.2017.6487

\section{RESUMO}

A educação ambiental tradicional não tem sido eficaz quanto à transformação das relações do homem com a natureza na direção do equilíbrio ecológico. O objetivo deste trabalho foi conhecer os significados de elementos de natureza presentes na música de Luiz Gonzaga, a fim de compreender a relação homem-natureza vivenciada pelo sertanejo do Nordeste. Para tal, foram selecionadas 10 músicas da obra de Luiz Gonzaga, as quais foram analisadas através da teoria/análise dialógica do discurso segundo Bakhtin, considerando a situação extraverbal de cada enunciação. Assim, foi revelado que a obra de Luiz Gonzaga possui elementos da natureza com relevantes significados que contribuem para a construção de uma relação mais estreita do homem nordestino com a natureza. Por isso, nos propomos a apresentar, como alternativa ao ensino tradicional, o uso da música como recurso metodológico, por ser essa expressão artística um grande veículo de significados, isto é, uma linguagem capaz de mobilizar as subjetividades dos alunos, facilitando, assim, a interiorização dos significados pertinentes.

PALAVRAS-CHAVE: Educação Ambiental, Luiz Gonzaga, Etnomusicologia, Bakhtin.

\section{STUDY OF MAN-NATURE RELATIONSHIP IN LUIZ GONZAGA'S REPERTOIRE: CONTRIBUTION TO ENVIRONMENTAL EDUCATION}

\section{ABSTRACT}

Traditional environmental education has not been effective in transforming man's relationship with nature towards ecological balance. This paper aims at exploring the meanings of elements of nature within in the music of Luiz Gonzaga, to understand the man-nature relationship established by the man of the Brazilian northeastern semi-arid. For that, 10 songs of Luiz Gonzaga's repertoire were selected and analyzed through the dialogical theory/analysis of the discourse, according to Bakhtin, taking into consideration the extraverbal situation of each statement. It was revealed
\end{abstract}

that the repertoire of Luiz Gonzaga has elements of nature with relevant meanings that contribute to the construction of a closer relationship between the Brazilian northeastern man and nature. Therefore, we intend to present the use of music as a methodological resource, as an alternative to traditional teaching, for that artistic expression is a great vehicle of meanings, a language capable of reaching the subjectivity of the students, thereby, facilitating the internalization of relevant meanings

KEYWORDS: Environmental Education. Luiz Gonzaga. Ethnomusicology. Bakhtin. 


\section{INTRODUÇÃO}

O estilo de vida que predomina nas grandes cidades tem nos tornado cada vez mais distantes da natureza, dificultando a nossa interação com esta, de modo que não nos sentimos integrados enquanto parte dela constituinte. Esse distanciamento parece ser um forte obstáculo à implementação de medidas capazes de resolver, efetivamente, os problemas ambientais, apesar da grande disponibilidade de técnicas de manejo dos recursos naturais.

Além disso, as novas tecnologias têm modificado progressivamente as relações de trabalho e se interpõem cada vez mais entre o homem e a natureza, o que promove a alienação das pessoas quanto à sua autoria nos processos de degradação do ambiente, agravando o problema uma vez que passamos a atribuir a responsabilidade dos cuidados com o meio ambiente a terceiros. Estamos imersos numa configuração de sociedade que vai na contramão da harmonia entre homem e meio ambiente desde a Revolução Industrial e a consolidação do capitalismo predatório atual.

Apesar da existência de cursos na área de gestão ambiental, o ensino tradicional voltado aos problemas ambientais e ao domínio das tecnologias capazes de revertê-los parece não ser suficiente. Constata-se que há um apelo por uma educação demasiadamente racional e técnica e que esta não tem alcançado seus objetivos. Sato (2001) aponta a necessidade de uma ruptura com esse modelo acadêmico-mecanicista de ensino.

Neste estudo nos propomos a conhecer a dimensão subjetiva da interação homemnatureza, partindo da ideia de que esta também é construída intersubjetivamente e de que o seu reconhecimento é fundamental à educação ambiental. Subjetividade é aqui entendida como o ambiente psicológico íntimo de indivíduos inseridos social e historicamente em uma cultura, de indivíduos dialogicamente interanimados ${ }^{1}$ que se relacionam com sua realidade material através de mediação semiótica². Segundo Bakhtin (2006):

[...] o psiquismo subjetivo localiza-se no limite do organismo e do mundo exterior, vamos dizer, na fronteira dessas duas esferas da realidade. É nessa região limítrofe que se dá o encontro entre o organismo e o mundo exterior, mas este encontro não é físico: o organismo e o mundo encontram-se no signo. (Bakhtin, 2006, p. 48)

A música se apresenta como uma das manifestações culturais mais carregadas de subjetividade. Sendo assim, ela expressa e, ao mesmo tempo, molda, as concepções de mundo das pessoas, podendo influenciar nas diversas formas de relação que elas estabelecem com seu meio social e natural. Adotamos o pressuposto de que músicas cujas letras são ricas em elementos do meio natural veiculam significados sobre este, podendo ser tomadas como objeto de estudo quando se deseja compreender a subjetividade humana presente na relação homem-natureza e a produção de sentidos que esta relação exige.

A música do cantor e compositor Luiz Gonzaga, cuja obra é considerada como uma das maiores expressões da cultura nordestina, possui letras repletas de elementos da natureza, uma

\footnotetext{
1 “[...] os enunciados de uma pessoa estão sempre em contato com, ou são endereçados a uma ou mais pessoas, e esses se interanimam mutuamente, mesmo quando os diálogos são internos” (Spink; Medrado, 2004, pág. 45)

2 “[...] a mediação pressupõe que nunca estamos livres das dificuldades impostas pelos instrumentos culturais ou como preferimos, impostas pelos seus significados implícitos ou explícitos”(Werstch, 1995 apud Fávero, 2005, pág. 19)
} 
vez que retrata a dependência do homem nordestino das condições naturais do sertão onde o artista viveu.

Conforme discorre Dreyfus (2012) sobre a biografia do artista, Luiz Gonzaga do Nascimento nasceu no dia 13 de dezembro de 1912, em Exu-PE. Já na infância, Gonzaga acompanhava seu pai Januário nos consertos de fole. Seu Januário, por sua vez, logo que percebeu o talento do menino, passou a levá-lo consigo para animar as festas. E, assim, era iniciado nos "bailes" mais um sanfoneiro do sertão nordestino.

Logo, aos 18 anos incompletos, decide sair de casa e entrar para o Exército. Como soldado, retoma sua atividade musical como corneteiro e, mais tarde, conhece o mestre Domingos Ambrósio, com quem volta a estudar sanfona. Logo, em 1939, largou o Exército e foi seguir carreira musical no Rio de Janeiro, tocando os sucessos da época até ser convencido a resgatar sua musicalidade sertaneja, com as canções que seu pai Januário Ihe ensinara.

Sua obra percorreu o Brasil fazendo sucesso e pautando temáticas da vida cotidiana das pessoas do sertão e sua forma de se relacionar, principalmente com a natureza. E, assim, o artista se tornou símbolo tão forte da identidade nordestina que mesmo com a ascensão da bossa-nova, cantores jovens continuaram reconhecendo a grandeza de Gonzaga e regravaram muitas de suas canções. Luiz Gonzaga falece em 2 de agosto de 1989, tendo imortalizado uma obra de 56 discos e mais de 500 preciosas canções.

Por ter grande alcance de público, acreditamos que a música Gonzagueana é importante difusora de significados na região Nordeste do Brasil, podendo ser esta uma forma relevante de reforço da identidade nordestina e, seu estudo, muito revelador da forma como o homem nordestino se relaciona com a natureza.

Encontramos em Bakhtin as ferramentas ideais para estudar a relação homem-natureza presente na obra de Luiz Gonzaga. Bakhtin, ao contribuir para a concepção de uma "análise/teoria dialógica do discurso" de modo a considerar a contextualização histórica, cultural e social da produção de discursos (Brait, 2006), nos fornece condições teórico-metodológicas para desvelar os diversos significados dos elementos da natureza presentes na obra de Gonzaga, nos fornecendo indícios de como o vínculo do homem com a natureza se constrói e se refaz no tempo e no espaço.

De acordo com Morin (2011), os cuidados com a natureza dependem do nosso sentimento de pertença ao próprio lugar. Significa dizer que a nossa identidade necessariamente é também composta pelos significados dos vários elementos da natureza presentes em nossa mente e pelas nossas atitudes em relação a esses elementos, que são consequências desses mesmos significados. Deste modo, ao considerarmos as expressões artísticas como veiculadoras de significados, ou seja, produtoras e reprodutoras da cultura, se pode questionar a respeito do papel da música cantada por Luiz Gonzaga no desenvolvimento de significados dos elementos da natureza para o povo nordestino.

Assim, chegamos às seguintes questões de pesquisa: quais são os elementos da natureza presentes na obra de Luiz Gonzaga?; quais são os possíveis significados atribuídos a esses elementos nos enunciados e vozes das composições interpretadas pelo artista?; como a relação 
do homem nordestino com a natureza é retratada na música de Luiz Gonzaga?; como a relação homem-natureza é estimulada na obra de Luiz Gonzaga?

Portanto, o presente estudo tem por objetivo geral conhecer os significados de elementos da natureza expressos por Luiz Gonzaga e seus interlocutores em sua obra. De modo que tivemos como objetivos específicos: identificar os elementos da natureza presentes nas músicas; verificar como os elementos identificados retratam a relação de Luiz Gonzaga e seus interlocutores com a natureza; discutir como esses significados de natureza são formadores da identidade nordestina; discutir a utilização da música como recurso didático na educação ambiental.

\section{REVISÃO BIBLIOGRÁFICA}

\subsection{Teoria/análise dialógica do discurso segundo Bakhtin}

No presente estudo procuramos trazer à tona os processos de produção de sentidos de "natureza" para o homem do sertão nordestino e como estes sentidos são veiculados e ressignificados.

Por que estudar essa dimensão subjetiva visando contribuir nos processos de formação em educação ambiental? Segundo Moscovici (2005), são os significados das coisas que estabelecem as formas de como o homem interage com seu meio social e natural. Por isso, questionamos acerca da relevância que a produção dos significados dos elementos que compõem a natureza tem sobre a forma como nos relacionamos com esta. Em outras palavras, desta perspectiva, pode-se sugerir que é a qualidade do nosso vínculo com os elementos da natureza que definirá se essa relação será ecologicamente equilibrada ou não.

Bakhtin (2006, apud Brait, 2014), um dos maiores estudiosos voltados ao fenômeno da linguagem, afirma que os significados são incorporados na nossa subjetividade a cada oportunidade de diálogo, de comunicação, de interanimação dialógica, presentes nas mais variadas formas de interação social. Em outras palavras, é durante os diálogos que o mundo ganha significados, que este mundo é refletido e refratado na subjetividade de cada indivíduo e, por conseguinte, devolvido ao meio social (Berger; Luckmann, 2007).

Ao construir sua análise/teoria dialógica do discurso, Bakhtin (2002 apud Brait, 2006) se preocupa em explicar como os significados são construídos, reproduzidos e modificados sob a influência das condições materiais, ambientais e históricas em que os diálogos entre as pessoas são estabelecidos.

Segundo Bakhtin, enunciado é a fala verbalmente articulada por um indivíduo em decorrência de uma situação extra-verbal vivenciada por este na relação com os seus interlocutores (Brait, 2006). Conforme Bezerra (2016), Bakhtin utilizou o termo russo "viskázivat" significando "ato de enunciar, de exprimir, transmitir pensamentos, sentimentos, etc. em palavras". Para Voloshinov apud Brait (2014), pesquisador do círculo de Bakhtin, os enunciados têm como causas a situação extraverbal: "a enunciação bombeia energia de uma situação da vida para o discurso verbal, ela dá a qualquer coisa linguisticamente estável o seu momento histórico vivo, o seu caráter único". Assim, qualquer enunciado possui caráter histórico, "por isso, liga-se a enunciações anteriores e a enunciações posteriores, produzindo e fazendo circular discursos" (Brait, 2014, p. 68). 
No que se refere a enunciados presentes em obras artísticas, é importante destacar a seguinte afirmação de Brait: "No ato artístico especificamente, a realidade vivida, já em si atravessada por diferentes valorações sociais, porque a vida se dá num complexo caldo axiológico, é transposta para um outro plano axiológico, o plano da obra" (Brait, 2014, p.38).

Ainda, referindo-se às várias formas de produção artística, Bakhtin apud Brait (2014, p. 162) afirma que "uma obra funciona como a réplica de um diálogo". É assim, portanto, que iremos tomar para análise a obra de Luiz Gonzaga, considerando-a enquanto entidade dialógica, veiculadora, reprodutora e refratária dos significados que permeiam as relações do homem nordestino com a natureza.

\subsection{A prática pedagógica em Educação Ambiental: um breve histórico}

As questões ambientais só passaram a ser debatidas muito recentemente. O mesmo, como consequência, vale para a Educação Ambiental. Segundo Machado (2013), os primeiros registros dos quais se tem notícia do termo "Educação Ambiental" foram feitos em 1948, num encontro da União Internacional para a Conservação da Natureza (UICN).

No entanto, somente nos anos 60 a discussão ganhou proporções significativas até culminar com grandes encontros internacionais, como a Conferência de Estocolmo, o Encontro de Belgrado, a Conferência Intergovernamental de Educação Ambiental e a Eco-92, que definiram princípios norteadores para a Educação Ambiental, apontando sua necessidade, definindo os agentes que devem estar envolvidos nesse processo e recomendando seu caráter contínuo, multi, inter e transdisciplinar.

Durante a realização do presente estudo foi constatado que a Educação Ambiental tem sido trabalhada nas Instituições de Ensino com os mesmos métodos que são aplicados para outras áreas do conhecimento, principalmente se utilizando de ferramentas teórico-metodológicas das ciências exatas: são aulas, na maioria das vezes, expositivas, de conteúdos exclusivamente técnicos, que abordam apenas os dados acerca da degradação da natureza, as formas do manejo do ambiente que julgam conveniente ao mercado e as leis que regulamentam esse manejo. Lima (2004), referindo-se ao ensino tecnicista na educação ambiental, faz a seguinte afirmação:

\footnotetext{
O tecnicismo [...] destaca e prioriza os aspectos técnicos da questão ambiental, encontrando nessa dimensão tecnocientífica as explicações e soluções aos problemas socioambientais. Essa leitura da realidade, por se apoiar no saber da ciência que é reconhecido como o saber socialmente dominante, se reveste de um poder especial e aparece como argumento neutro, objetivo e portador de uma autoridade que o imuniza a qualquer questionamento (Lima, 2004, pag. 87).
}

Segundo Sato (2001), existem experiências lúdicas restritas a alguns espaços escolares, principalmente, no ensino fundamental, mas estas também não surtem grandes resultados, pois são, geralmente, esvaziadas de sentidos. A autora descreve assim essa prática:

Proliferam-se, assim, ações pontuais de abraçar árvores ou oficinas de reciclagem de papel, sem nenhuma postura crítica dos modelos de consumo vivenciados pelas sociedades, ou pela análise de modo de relação dominadora do ser humano sobre a natureza, com alto valor antropocêntrico. (Sato, 2001, pág. 3) 


\section{METODOLOGIA}

A discografia do cantor e compositor Luiz Gonzaga foi submetida a uma audição prévia e, a partir disso, foram selecionadas 10 músicas para a análise (Quadro 1), adotando-se o seguinte critério: presença, na letra da música, de elementos da fauna, flora, geologia/geomorfologia, fenômenos naturais e outros, evitando-se, ao máximo, músicas que continham os mesmos elementos, a fim de garantir uma boa diversidade nos resultados. Para tal, utilizamos o sítio de internet "Luiz Lua Gonzaga" (Vanderley, 2017) que dispõe de toda a obra do artista organizada cronologicamente e por disco.

Quadro 1: Relação das músicas selecionadas para análise.

\begin{tabular}{|l|l|}
\hline \multicolumn{2}{|c|}{ MÚSICA (n) } \\
\hline A triste partida (1) & Estrada de Canindé (6) \\
\hline Acauã (2) & No Ceará não tem disso, não (7) \\
\hline Acordo às quatro (3) & Súplica Cearense (8) \\
\hline Apologia ao jumento (4) & Vozes da Seca (9) \\
\hline Asa Branca (5) & Xote Ecológico (10) \\
\hline
\end{tabular}

Passamos, então, à análise do repertório selecionado, que foi qualitativa, tendo como principal referencial a teoria/análise dialógica do discurso de Bakhtin (2002), considerando o texto verbal e a situação extraverbal presente em cada enunciado. Assim, os resultados obtidos no presente estudo foram compostos das respectivas interpretações das músicas.

Durante o processo de análise, cada música foi, inicialmente, apresentada e situada historicamente e temporalmente no universo psicossocial do artista. Cada música foi tomada como um enunciado (E) e designada com um número $(n)$.

Numa primeira leitura das músicas foram identificados os elementos da natureza nelas contidos com a finalidade de orientar a interpretação dos enunciados em função do interesse da pesquisa. Estes elementos estão inicialmente apresentados ao longo do texto, seguidos de sua interpretação. Finalmente, foi feita uma discussão a respeito da aplicabilidade da música enquanto recurso didático alternativo às estratégias tradicionais de educação ambiental.

\section{RESULTADOS}

A seguir, apresentamos a análise dos 10 enunciados, realizada conforme indicado na metodologia, e também destacamos os elementos da natureza presentes em cada música.

a) A triste partida (1)

A triste partida foi originalmente um poema feito por Patativa do Assaré, em 1958. Há contradição quanto a quem lhe pôs a melodia, como expõe Pereira Neto (2012). Na versão que contava Patativa, dizia que Gonzaga tinha ouvido Zé Gonçalves entoar a canção numa rádio de Campina Grande e, impressionado, procurou o compositor, que seria o próprio Patativa. Noutra versão, o pesquisador Ricardo Cravo Albin conta que Gonzaga ouviu pessoalmente o poeta recitar os versos e decidiu musicá-los. O sanfoneiro ainda teria acrescentado à letra original o "meu Deus, meu Deus" e o "ai, ai", a contragosto do poeta. Fato é que, de uma maneira ou de outra, "A triste 
partida" foi enfim gravada pelo Rei do Baião em 1964 no LP homônimo e foi importantíssima para que a obra de Patativa tivesse alcance nacional.

Os elementos da natureza identificados na análise da música "A triste partida" (Enunciado 1) foram as seguintes para cada categoria: Fauna (cigarra, burro, jegue, cavalo, galo, cachorro); Flora (copa da mata, pé de fulô, pé de roseira); Geologia/geomorfologia(pedra de sal, terra, torrão, lama, serra, paú); Fenômenos Naturais (barra, chuva, verão, seca, garoa); Outros (céu, sol).

A letra da música é, a começar pelo título, uma narrativa do êxodo da população rural do Nordeste para o Sudeste. Durante a longa canção, Patativa explora detalhadamente o sofrimento do povo sertanejo com a seca até o momento em que as condições naturais do lugar passam a inviabilizar a vida no sertão para os mais pobres.

A seca é retratada, então, como o maior temor daquele povo, estando diretamente atrelada à fome. Logo nos primeiros versos, fica clara uma angústia na espera pela chuva. Neste momento, a sabedoria popular se confunde com a religiosidade e se configuram nos maiores apelos. Por exemplo, a "crença nas pedras de sal", que seriam indicativos de umidade na região e, consequentemente, prenúncio de chuva; e a fé na generosidade da Santa Luzia e São José, em 13 de Dezembro e 19 de Março, respectivamente.

Ainda que não haja relação comprovada entre o inverno e as chuvas no dia de São José, sabe-se que a data, muitas vezes, coincide com o equinócio de outono, quando há maior incidência do sol na linha do Equador e, assim, maior probabilidade de chuva. Embora haja um conhecimento do sertanejo a partir da sua experiência, para eles, as manifestações da natureza não ocorrem por razões naturais, mas por vontade de entidades místicas.

Além disso, há uma menção à espera pela "barra", que são as nuvens, no Natal. Com isso, o canto da cigarra na copa da mata representa, segundo a crença popular, ano de estio, o que, para o eu lírico, é confirmado com a posterior ausência de nuvens. Mais uma vez o aspecto religioso aparece como explicação: castigo. Novamente, a natureza expressa a vontade de Deus.

Portanto, a família do enunciado decide rumar para o Sul (forma genérica de designar o Sudeste e Sul) e para isso é necessário vender suas posses. As maiores riquezas do sertanejo são elementos da natureza, como o burro, o jumento e o cavalo: animais de muita serventia como transporte. Também o galo, além desses outros, aparece como animal de difícil desapego por parte da família. E apesar desse grande valor afetivo, a exploração dos fazendeiros sobre os migrantes prevalece e por pouco dinheiro a criação é vendida.

Durante a viagem, é da serra que se vê a terra deixada para trás e isto custa aos viajantes muita dor. A natureza do lugar, apesar de inóspita, é amada por eles, que se perguntam como ficará o cachorro, o gato, o "pé de fulô" e todo o ambiente.

Ao chegar em São Paulo, a família se sente vulnerável por estar inserida em um meio urbano. Logo, a garoa, a lama e o paú se tornam elementos repulsivos. Assim, os elementos da natureza são ressignificados e ganham conotação negativa no contexto da cidade. Submetidos a condições exploratórias, mais ainda do que já estavam submetidos no trabalho nas fazendas, os personagens perdem a perspectiva de voltar ao sertão e sofrem com a saudade de seu estilo de vida rural original. 
b) Acauã (2)

Acauã foi composta por Zé Dantas e gravada por Luiz Gonzaga no 78 RPM de 1952. Com forte base em crendices populares, a música tem como personagem principal a ave comum do sertão nordestino. Seu nome deriva do termo em tupi waka'wã, que significa "grande ave de rapina".

Os elementos da natureza identificados na análise da música "Acauã" (Enunciado 2) foram os seguintes para cada categoria: Fauna (acauã, João Corta-Pau, coruja, mãe-da-lua, peitica, bacurau, sapo, gia, rã); Fenômenos Naturais (verão, seca, chuva, inverno); Outros (sertão).

O canto da ave Acauã, na música e na crença popular, é retratado como sinônimo de agouro, um prenúncio da seca e, portanto, de sofrimento para o povo nordestino. A observação de um comportamento animal como este é indício de vínculo forte entre o sertanejo e a ave. Outro indício é a forma de se referir à ave, como que numa conversa, onde há o apelo para que se cale e permita a vinda da chuva.

A música põe as aves como elementos que caracterizam os tempos de chuva e de seca. Desta forma, Zé Dantas cita o João Corta-Pau, a coruja, a mãe-da-lua, a peitica (ave migratória que vive em baixas latitudes durante o inverno) e o bacurau como aves que cantam no sertão, mais precisamente à noite. Além destes, fala dos que cantam no inverno, provocando alegria no sertanejo: sapo, gia e rã. Mas por fim, lamenta o canto solitário e ameaçador da acauã, que só lhe suscita sentimentos de medo, pena e tristeza.

c) Acordo às quatro (3)

Em 1979, Luiz Gonzaga lança um LP chamado "Eu e Meu Pai", em homenagem ao Mestre Januário, que havia falecido no ano anterior. Nele, estão presentes músicas que retratam um Nordeste que sofre (Súplica Cearense), que ama (Orélia e Sorriso Cativante), que brinca (Manoelito Cidadão e Respeita Januário) e que trabalha (Acordo às quatro). Esta última foi composta por Marcondes Costa e eternizada na voz de Luiz Gonzaga.

Os elementos da natureza identificados na análise da música "Acordo às quatro" (Enunciado 3) foram os seguintes: Fauna (passarinho, miúça, carneiro, porco, galinha, vaca); Geologia/geomorfologia (terra); Outros (céu, ar).

A música "Acordo às quatro" é um retrato da rotina do sertanejo que trabalha na roça e vive de agricultura e criação de animais. É uma narrativa doce, repleta de muito carinho entre os personagens (o sertanejo, sua esposa, os filhos). O cuidado com o trabalho se funde com o cuidado com a família. Logo, o pai trabalha feliz na esperança de poder proporcionar a seus três filhos uma escolarização e, consequentemente, um futuro melhor.

Essa felicidade no trabalho também é resultado do ambiente saudável de que o trabalhador desfruta, como fica claro quando é mencionado o ar puro do lugar e o canto dos pássaros. Este é um trecho importante porque indica que o sertanejo já possui o referencial de um ar poluído e de meio ambiente ecologicamente desequilibrado. 
Assim, o personagem desenvolve uma noção de riqueza baseada na sua qualidade de vida, explicitada na música através do ar limpo, fauna preservada e do trabalho prazeroso na sua criação de animais (miúças, carneiros, porcos, galinhas e uma vaca).

Além disso, a relação estreita com o meio ambiente está presente quando o sertanejo utiliza o céu escuro como parâmetro temporal.

d) Apologia ao Jumento (4)

A música foi claramente inspirada na luta do Padre Antônio Batista Vieira pela preservação destes animais que ele considerou importantíssimos para o sertanejo. Padre Vieira foi autor de "O Jumento, nosso irmão", o que lhe rendeu fama internacional de "Protetor do Jegue". Percebendo que o animal vinha sendo exterminado, o padre organizou um movimento no Crato, em 1968, ao lado de Patativa do Assaré, José Clementino e Luiz Gonzaga, chamado "Trilogia do Ciclo do Jumento".

Neste mesmo ano, o movimento ganhou projeção nacional através da música "Apologia ao jumento", que foi composta por Luiz Gonzaga e José Clementino e teve sua primeira versão gravada em 1968, sob o título “O jumento é nosso irmão", no LP “O Sanfoneiro do Povo de Deus". Mais tarde, foi regravada já com o título atualizado no álbum Capim Novo (1976). Entre as duas pequenas estrofes é inserida uma longa que sofreu várias alterações ao longo do tempo, tendo ficado mais provocativa nesta última versão, que foi a versão escolhida para análise.

Os elementos da natureza identificados na análise da música "Apologia ao jumento" (Enunciado 4) foram os seguintes para cada categoria: Fauna (jumento); Flora (milho); Geologia/geomorfologia (água); Fenômenos Naturais (chuva); Outros (sertão).

Nesta música, o jumento é colocado como animal de grande serventia ao homem e a quem este deve muito respeito e companheirismo. O sentimento de fraternidade presente em sua relação com o jumento significa que este o reconhece praticamente como humano. Desta forma, são atribuídas ao animal características de solidariedade, malícia, traquinagem, perseverança e patriotismo. A música apresenta uma inversão de papéis quando o jumento aparece como professor, alfabetizando as pessoas, e os professores aparecem como jumentos.

Para além das características humanas, as crenças populares reconhecem no jumento um animal sagrado, por ter sido, segundo a lenda, transporte utilizado por Jesus. Assim, a relação entre o homem e o jumento passa a ser quase de devoção.

Por outro lado, temos a imagem do jumento humilhado, num trabalho forçado e sacrificante, que pode ser transportada para muitas formas de opressão na sociedade. O jumento que Luiz Gonzaga canta pode ser interpretado simplesmente como o trabalhador rural explorado pelos seus coronéis que, posteriormente, sequer reconhecem sua importância. Ou mesmo pode ser uma metáfora para a relação predatória estabelecida com a natureza, que garante o sustento do homem.

Paralelamente à história principal, Gonzaga descreve o hábito de plantar milho doce nas primeiras chuvas do sertão. O costume é justificado pela rapidez do nascimento do milho, representação do sucesso do plantio e garantia de boa safra nas próximas chuvas. 
Também vale ressaltar a menção a aspectos animais através de referências tecnológicas, como quando o levantar de orelhas do jumento é descrito como "ligar as antenas". Isto mostra uma aproximação entre dois mundos: o natural e o artificial. Observar similaridades entre estes universos é uma forma que o sertanejo encontra de internalizar e se apropriar dos avanços tecnológicos.

Num arremate final, depois de ter sido colocado como meio transporte de pessoas, de carga e da tão preciosa água, o autor põe sobre este animal a responsabilidade sobre o desenvolvimento nacional. O jumento é, enfim, homenageado e gratificado.

e) Asa Branca (5)

Antes de ser imortalizada pela sanfona do Rei do Baião, a melodia de Asa Branca já era um tema folclórico de domínio público no Nordeste, tendo sido tocada por vários sanfoneiros da região de Gonzaga, inclusive seu pai Januário.

Mais tarde, o sanfoneiro conhece um dos seus principais parceiros, o advogado Humberto Teixeira. Com ele, põe letra na canção e a registra em vinil no ano de 1947. Asa Branca se tornou tão representativa da vida do nordestino que passou a ser conhecida como Hino do Nordeste.

Os elementos da natureza identificados na análise da música "Asa Branca" (Enunciado 5) foram: Fauna (gado, alazão, asa branca); Flora (plantação); Geologia/geomorfologia (terra, água); Fenômenos Naturais (chuva); Outros (sertão).

Sendo a música mais emblemática da obra de Luiz Gonzaga, Asa Branca coloca a referida ave como símbolo maior da identidade nordestina, uma vez que, assim como em "A volta da Asa Branca", as vivências da ave e do sertanejo, quanto às suas relações com a natureza, tem relevantes pontos comuns que são responsáveis pela identificação entre os dois.

Cantada em primeira pessoa, a música tem, desde o início, um caráter de lamento. Há uma comparação entre a terra aquecida na seca e a alta temperatura de uma fogueira em festejos juninos. O primeiro cenário é a representação do que há de mais penoso para o sertanejo; o segundo, o oposto, um elemento comemorativo, mas trazendo a visão da madeira sendo consumida pelo fogo. Visto que a realidade vivenciada é a primeira, o sertanejo chega ao ponto de atribuir o seu sofrimento a causas divinas e, assim, questiona as motivações de Deus.

O sertanejo, então, conta suas perdas decorrentes da seca. Fica claro o quanto a ausência de água é fator causal da morte da plantação e dos animais, neste caso, o gado e o alazão. A estes elementos é atribuído grande valor, afinal, o trabalho do homem comum do campo gira em torno da agricultura e da criação de animais. Estes elementos naturais constituem, portanto, a forma de sobrevivência do sertanejo. Não sendo possível o seu manejo, a vida no sertão torna-se insustentável.

A música atinge um momento decisivo quando o eu lírico observa a partida da Asa Branca como uma razão para também partir. O comportamento da ave é, portanto, associado ao êxodo rural vivenciado por uma parcela significativa da população nordestina, como uma espécie de "sina compartilhada". 
A despedida do sertão é repleta de esperanças sobre um possível retorno à terra natal e ao estilo de vida rural, onde o contato com a natureza é imensamente mais intenso e direto. $\mathrm{O}$ eu lírico também se despede temporariamente de uma mulher amada, chamada Rosinha. Curiosamente, até seu nome desperta uma referência à delicadeza da flores e à fertilidade.

Finalmente, distante do sertão, sentindo-se só e deslocado, o eu lírico se apega à promessa de voltar à amada, assim que as condições naturais Ihe permitirem. Em suma, o eu lírico idealiza um sertão semelhante aos olhos da amada, cuja cor verde lhe proporciona sensação de acolhimento comparável ao ambiente chuvoso e fértil.

f) Estrada de Canindé (6)

Esta música foi composta por Luiz Gonzaga e Humberto Teixeira e gravada pela primeira vez em 1951. A começar pelo título, a música faz uma explícita referência ao município de Canindé, no norte do estado do Ceará. Depois de ter feito sucesso na voz de Luiz Gonzaga, a música foi regravada por vários artistas, como Fagner, Elba Ramalho e Mariene de Castro.

Os elementos da natureza identificados na análise desta música foram: Fauna (burrico, galo campina); Flora (flor); Geologia/geomorfologia (riacho, água); Fenômenos Naturais (orvalho); Outros (sertão, lua).

Estrada de Canindé é musical e poeticamente suave, cheia de calma, seja por seu andamento e melodia arrastados, seja por suas expressões que denotam tranquilidade como o "Ai, ai, que bom".

Percebe-se que, inicialmente, o cenário noturno potencializa ainda mais este clima de sossego, com a lua sendo posta como elemento chave. O sertão aqui é retratado por seu lado mais encantador, ocultando-se as mazelas de um povo que sofre continuamente com a seca, geração após geração. O meio ambiente é aqui retratado na sua capacidade de propiciar prazer ao sertanejo.

De repente, duas temáticas se cruzam: os meios de transporte no sertão e as classes sociais. O poder aquisitivo do indivíduo está diretamente relacionado à sua forma de se deslocar. Por conseguinte, a forma de se deslocar determina a relação que o indivíduo estabelecerá com a natureza no seu trajeto.

Embora a forma mais sofisticada de transporte colocada na música seja o automóvel, o burro é o meio de transporte mais usado pelos mais ricos do sertão. Os pobres andam a pé. Para a surpresa do ouvinte, os autores praticamente põem em xeque o conceito de pobreza ao revelar a exuberância vivida por quem interage diretamente com os elementos da natureza, sem entremeios que os distanciem. Neste sentido, o burro e o automóvel representam isolamentos de boa parte dos detalhes das belezas naturais, como o orvalho na flor, a cor do Galo de Campina e a sensação de molhar os pés no riacho.

Pode-se dizer, então, que o sertanejo não atribui a sua qualidade de vida às suas posses materiais ou ao seu dinheiro, mas sim ao seu contato simples, prazeroso e saudável com a natureza. Isto tem um poder enorme sobre sua conviç̧ão e habilidade em preservar o meio ambiente. 
g) No Ceará não tem disso, não (7)

Em 1950, Luiz Gonzaga grava uma música do pernambucano Guio de Morais, o sucesso “No Ceará não tem disso, não". Tendo morado no Rio de Janeiro desde 1939, já tem opinião formada sobre as diferenças entre a vida numa grande metrópole do Sudeste e numa pequena cidade nordestina. A música de Guio, então, se mostra como representativa de suas observações.

Os elementos da natureza identificados na análise da música "No Ceará não tem disso, não" (Enunciado 7) foram os seguintes para cada categoria: Fauna (cobra, tubarão); Fenômenos Naturais (chuva, inundação); Outros (sertão).

O personagem principal na música é um cearense chocado com a realidade natural e humana das grandes cidades. Dado o seu contexto original de aridez, a chuva para ele só poderia ser elemento causador de alegria. No entanto, na cidade de solo impermeabilizado pelas vias asfaltadas, a pouca chuva que cai gera inundações e provoca transtorno. Essa ressignificação é rejeitada pelo sertanejo e a situação é tida como bizarra. Logo, ao comparar os contextos, fica clara a preferência pelo sertão, onde a chuva penetra o solo e permite o crescimento das plantas.

Também é notável a rejeição pela esperteza das pessoas da cidade grande. As moças vestidas de cobra podem ser aqui interpretadas de duas formas. Ou são mulheres cheias de maldade, havendo a associação da peçonha cobra a uma personalidade perversa; ou é uma referência às estampas das roupas de pessoas que, sem contato com as cobras, banalizaram o significado forte que este animal pode possuir no senso comum. Há ainda a figura do "tubarão", cuja ferocidade e crueldade podem ser alusivas à figura de um explorador, um aproveitador da condição do retirante que vai comprar alguma coisa.

O personagem aflito com a situação finalmente conclui que seu maior desejo é retornar, assim que possível, ao seu lugar de pertencimento, sua terra, seu sertão. Só assim para fugir do estilo de vida urbano que ele considera estranho.

h) Súplica Cearense (8)

Súplica Cearense é uma composição de Gordurinha e Nelinho. A música nasceu nos bastidores de um programa de tv que estava arrecadando dinheiro como auxílio à população que havia sofrido com enchentes no Nordeste. Assim, foi apresentada ao vivo e depois, no ano de 1960, foi gravada pelo próprio Gordurinha, chegando a vender 400 mil cópias. Apenas 24 anos mais tarde, Gonzaga registrou a canção no LP "Luiz Gonzaga e Fagner".

Os elementos da natureza identificados na análise da música "Súplica Cearense" (Enunciado 8) foram os seguintes: Flora (planta); Geologia/geomorfologia (chão, água); Fenômenos Naturais (chuva, inverno); Outros (sol).

Súplica Cearense é, conforme o título já sugere, uma música penosa sobre um povo que implora por piedade. Dado o contexto de sua composição, os cearenses agora sofrem por um motivo diferente daquele que estão acostumados a lidar: o excesso de chuvas. Nesse caso, a chuva é ressignificada, ao invés de um fenômeno que produz fartura e alegria, passa a representar o desabrigo de muita gente por um castigo divino. 
O eu lírico se culpa por ter pedido chuva a Deus num tempo em que sofria com a seca, no qual a água nos olhos era a única presente. Pede perdão por ter importunado a Deus pedindo de modo insistente pelas chuvas. No entanto, se explica: a chuva deveria ser apenas o suficiente para aguar o chão (a terra) e favorecer a plantação, acabando com o sofrimento do povo do sertão com a seca. Ao invés disso, a chuva veio em tamanha abundância que atingiu o outro extremo, causando a dor, agora devido às inundações.

A seca, então, é comparada ao inferno. Seu oposto, a chuva, deveria ser algo comparável ao paraíso, o que o sertanejo constata que não é sempre verdade. Logo, o pedido de desculpas pode também ser interpretado como uma ironia ou uma incompreensão da vontade divina, afinal, o sertanejo só pedia o justo, a chegada do inverno que lhe proporcionaria o mínimo possível para viver.

i) Vozes da seca (9)

A música é uma composição de Zé Dantas e Luiz Gonzaga, gravada no 78 RPM de 1953, ano em que o Nordeste sofreu com um grande estio, até que foi decretado Estado de Emergência e teve início uma grande campanha de doação de roupas e alimentos para as vítimas da seca. No entanto, os compositores concluíram que, para resolver definitivamente o problema da seca, era preciso uma ampla política de Estado. Em 1981, a música foi regravada no disco "A vida de viajante". Nesta versão, Gonzaga faz uma fala de agradecimento a Juscelino Kubitschek pela criação da Superintendência do Desenvolvimento do Nordeste (SUDENE), em 1959.

Os elementos da natureza identificados na análise da música "Vozes da Seca" (Enunciado 9) foram os seguintes para cada categoria: Fenômenos Naturais (seca, chuva); Outros (sertão).

"Vozes da Seca" é uma canção de protesto diante da forma como o povo do Sudeste estava lidando com a seca nordestina. Apesar da gratidão pela solidariedade através da doação de alimentos e roupas, os compositores acreditam que isto ainda é uma "esmola" em relação ao que seria realmente necessário para cessar o sofrimento com a seca a longo prazo. A letra sugere que, para os nordestinos, é uma vergonha aceitar tão pouco, tornando-os dependentes desse auxílio em cada recorrência do fenômeno natural.

Em seguida, a dimensão do problema é apresentada. A fome está assolando quase metade do país. No momento do clamor por ajuda, nos deparamos com um ponto chave desta letra: a responsabilidade sobre o convívio com a seca não é mais atribuída exclusivamente a um Deus, mas sim a homens, especificamente homens detentores de poder político.

Dessa forma, o eu lírico passa a apostar em novas formas de organização social e em tecnologias como forma de garantir a água para todos durante o estio. Criação de empregos, construção de barragens e açudes e barateamento do preço das comidas aparecem como alternativas para libertar o povo dos auxílios.

Como retorno, o povo trabalhador do Nordeste conseguiria boas safras e, consequentemente, contribuiria para a geração de riquezas para todo o país. Aqui, a garantia das plantações é sinônimo não só de vida digna para a população, mas também de desenvolvimento nacional. 


\section{j) Xote Ecológico (10)}

Xote Ecológico é uma parceria de Luiz Gonzaga com o pernambucano Aguinaldo Batista. A canção abre o lado B do disco "Vou te matar de cheiro", gravado em 1989, o antepenúltimo da carreira de Luiz Gonzaga. É uma das canções mais representativas da defesa que Gonzaga fazia da harmonia ecológica.

Os elementos da natureza identificados na análise da música "Xote Ecológico" (Enunciado 10) foram: Fauna (peixe); Flora (flor, verde); Geologia/geomorfologia (terra); Outros (mar).

"Xote ecológico" é uma letra que mostra a percepção ambiental dos compositores nas últimas décadas do século XX, quando o modelo de grandes cidades atinge também essas regiões. A grande quantidade de automóveis e indústrias implica num alto grau de poluição que não passa despercebido por quem construiu vínculo forte com um meio ambiente ecologicamente equilibrado.

Com tom de protesto, o eu lírico reclama da poluição do ar e da água que o impossibilitam nadar e respirar com a qualidade devida. Também ocorre um antropomorfismo da terra, que está a morrer, nutrindo mal a plantação. A monocultura canavieira aparece como um problema implícito, quando a letra diz que nem cachaça boa se encontra mais, afinal, um solo empobrecido não pode render colheitas de boa qualidade.

Como cobrança, o eu lírico pergunta pela flora e pela fauna e responsabiliza os poluidores pela devastação. Finalmente, sugere que estes poluidores possuem fortes interesses que os levam, inclusive, ao assassinato do ativista ambientalista Chico Mendes. A defesa do meio ambiente ganha aqui um caráter político fortíssimo.

\section{DISCUSSÕES}

\subsection{Da vida para a obra, da obra para a vida}

Ao buscar caracterizar a relação homem-natureza na obra de Gonzaga a partir do olhar de Bakhtin, fizemos o reconhecimento contextualizado dos elementos da natureza presentes nesses enunciados e os interpretamos de modo a fazer emergir deles seus significados, manifestos ou latentes, valorizando também seus aspectos afetivos e motivacionais, bem como o sentimento de pertença do homem nordestino ao seu meio social e natural.

Os resultados nos mostram o que é sugerido pelo círculo bakhtiniano a respeito de como ocorre a produção de sentidos a partir do dialogismo permanente entre interlocutores: nos intercâmbios enunciativos a vida do homem sertanejo é refletida e refratada na obra de Gonzaga que, por sua vez, serve de veículo mantenedor dos significados que esta contém, na região Nordeste ao longo do tempo. Como isto se fez presente nas músicas que foram analisadas?

As canções de Luiz Gonzaga analisadas personificam a fauna e a flora uma vez que o eu lírico dialoga, por exemplo, com a 'acauã', com o 'juazeiro' e com o 'jumento' como se estes fossem providos de atributos humanos. Esses significados, assim, tendem a colocar a natureza e o homem em pé de igualdade. Este entendimento é corroborado nas análises quando estas revelam também que a felicidade e o sofrimento, em decorrência das chuvas ou das secas, são comuns ao homem e à natureza. 
O sustento do homem sertanejo é retratado nas análises enquanto advindo da relação direta deste com a natureza. Muito frequentemente há referência às atividades de agricultura e à criação de animais, sendo os elementos relacionados a essas atividades considerados seus únicos patrimônios; o que fica claro pela dor expressa quando ocorre o afastamento de sua terra natal. Assim, como os elementos da natureza são tidos como seus únicos patrimônios, preservá-los significa praticamente preservar a própria vida, seus hábitos, costumes, sua própria identidade. Desta forma, os resultados aqui encontrados corroboram com a ideia de Sato:

A natureza nunca pode ser separada de alguém que a percebe, ela nunca pode existir efetivamente em si porque suas articulações são as mesmas de nossa existência e porque ela se estabelece no fim de um olhar ou ao término de uma exploração sensorial que a investe de humanidade (Sato, 2001).

Também com frequência, a natureza é tida como fonte de deleite pelo sertanejo. As análises revelam que o estilo de vida no sertão, pelas características das atividades desenvolvidas, faz com que o tempo do homem coincida com tempo da natureza. A hora do trabalho é indicada pelos animais ou pelo nascer e por do sol, o tempo da colheita é também o tempo das festas, o tempo propício aos matrimônios. A alternância entre as condições ambientais, propícias ou não ao trabalho, permite ao sertanejo também um tempo para contemplação, o que não acontece na cidade.

O inverno e a seca são dois fenômenos amplamente retratados na obra de Gonzaga. A relação do nordestino com esses fenômenos é permeada por alegrias e sofrimentos intensos, muitos projetados em elementos como aves e outros animais. Às vezes, um mesmo elemento sendo depositário, em dependência do contexto, de significados antagônicos, como é o caso da asa branca, que indica bom presságio quando se faz presente no sertão e mau presságio quando se ausenta.

Os enunciados denunciam que o homem nordestino se percebe impotente diante da seca e atribui a responsabilidade de alguma mudança nessas condições às suas divindades. Mas também não deixa de expressar o conhecimento de que a intervenção humana, por exemplo, através do acúmulo de água em açudes, pode tornar menos doloroso o convívio com a seca.

Por outro lado, o inverno, sinônimo de fartura, é o tempo das festas. No entanto, a mesma chuva que habitualmente representa a alegria pode ser ressignificada num contexto em que o seu excesso produz condições adversas. O sertanejo descobre, então, outra relação possível com a água, seja por causas naturais, como é o caso das enchentes atípicas no sertão nordestino; seja pelas inundações decorrentes da impermeabilização do solo nas grandes cidades. Também a lama é ressignificada: o massapê pode ser tanto indicador de um terreno fértil, como pode se tornar componente de um cenário insalubre, no qual há exploração do trabalho do imigrante nordestino no Sudeste.

Desta forma, os resultados das análises das músicas reforçam a ideia de que a construção de um enunciado numa obra artística depende dos discursos circulantes no contexto de sua criação e enunciação e incorpora as condições ambientais e sociais subjetivas e objetivas desse contexto. Ou seja, as vivências comuns às pessoas de um grupo social, estabelecidas a partir da sua cultura, são apropriadas pelo enunciador, que faz da sua obra também um espaço de 
afirmação da sua subjetividade e identidade, de reposição de significados já existentes e, como consequência, contribui com a permanência, ao menos parcial - parcial porque alguns elementos poderão ser ressignificados -, das características das relações com a natureza já estabelecidas. Dáse, então, um movimento dialógico que retroalimenta a cultura, uma vez que os significados transitam da vida para obra e desta para a vida.

\subsection{Uma questão de identidade}

Segundo Berger e Luckmann (2007, pag. 174), ao nascer, nós interiorizamos e "assumimos o mundo em que os outros já vivem" e apreendemos o mundo como realidade dotada de sentido. Ou seja, os significados das coisas, os sistemas de valores e as formas de se relacionar com as pessoas e a natureza presentes na cultura nos são, a princípio, compulsoriamente emprestados, embora ao compor a nossa subjetividade estes sejam parcialmente modificados.

A partir da cultura, desenvolvemos então as várias formas de relação com a natureza. A linguagem, expressa nos enunciados circulantes, é o veículo para a interiorização desses significados e através dela estes norteiam nossas atitudes diante das pessoas e do mundo (Moscovici, 2005).

É nessa trama de discursos de sujeitos situados no tempo e no espaço, que se configuram as identidades:

Para compreendermos melhor a ideia de ser a identidade constituída pelos grupos de que fazemos parte, faz-se necessário refletirmos como um grupo existe objetivamente: através das relações que estabelecem seus membros entre si e com o meio onde vivem, isto é, pela sua prática, pelo seu agir (Lane, 2006, p.64).

Percebe-se na música de Gonzaga que os significados de natureza estabelecem um conjunto de fazeres próprios do homem sertanejo nordestino, que caracteriza sua identidade no que se refere a forma como esses se relacionam com a natureza.

Desta feita, podemos sugerir que a música, enquanto veículo de significados nos discursos circulantes legitima a identidade do homem nordestino e contribui efetivamente para manutenção de seus modos específicos de relação com a natureza. No dizer de Lane $(2006$, p.66) "re-atualizamos através de rituais sociais uma identidade pressuposta que assim é reposta".

Mas são também as condições materiais contingentes que modificam as relações do homem com a natureza. Dentre os fatores que interpuseram obstáculos ao contato direto entre esses estão o estilo de vida nas grandes cidades e os avanços tecnológicos, uma vez que nos possibilitaram romper as fronteiras do espaço e do tempo:

Nas sociedades pré-modernas, o espaço e o lugar eram amplamente coincidentes, uma vez que as dimensões espaciais da vida social eram para a maioria da população dominadas pela presença - por uma atividade localizada... A modernidade separa, cada vez mais, o espaço do lugar, ao reforçar relações entre outros que estão "ausentes", distantes (em termos de local), de qualquer interação face-a-face. Nas condições da modernidade..., os locais são inteiramente penetrados e moldados por influencias sociais bastante distantes deles. O que estrutura o local não é simplesmente aquilo que está presente na cena; a "forma visível" do local oculta as relações distanciadas que determinam sua natureza (Giddens apud Hall, 1992, p. 72) 
A relação com a natureza é, portanto, comprometida. Os meios de sobrevivência não estão mais na dependência de uma relação homem-natureza tão íntima e profunda como expressa na música de Gonzaga: nos enunciados do artista o homem chega a se confundir com a própria natureza.

Corroborando com esta ideia de ruptura do homem com a natureza, que se acentuou a partir da modernidade, e da nossa percepção sobre esta, Morin (2011, p. 55) escreveu sobre a necessidade de recuperar a nossa 'identidade terrena, afirmando que "na era das telecomunicações, da informação, da internet, estamos submersos na complexidade do mundo as incontáveis informações sobre o mundo sufocam nossas possibilidades de inteligibilidade". Vemos sutilmente na obra de Luiz Gonzaga uma leitura sobre esse fenômeno do distanciamento do homem em relação natureza na música "Estrada de Canindé".

\subsection{Por um enunciado verbo-musical como ferramenta pedagógica}

Há uma carência na existência de recursos didático-pedagógicos voltados especificamente à Educação Ambiental, o que indica o uso de estratégias comuns a outras áreas. A formação nessa área segue, geralmente, ocorrendo com aulas expositivas centradas no professor e com conteúdos apenas técnicos.

Muitas são as discussões acerca da eficiência dos métodos considerados "duros" no ensino. São métodos centrados nos conteúdos ou no professor, que não dão conta de encontrar nos próprios alunos os seus saberes para estimular que eles mesmos construam o seu conhecimento, e que desprezam a multidimensionalidade do ser humano. Assim, os aspectos subjetivos são ignorados, privilegiando-se a racionalidade técnica.

Quando Morin (2011) escreveu "os sete saberes necessários à educação do futuro" ele destacou que o conhecimento pertinente deve levar em conta as múltiplas dimensões que compõem o ser humano, a saber, sua biologia, seu psiquismo, seu pertencimento social, seus afetos e sua racionalidade. Ainda, critica o conhecimento especializado, as disciplinas compartimentadas, dizendo que este negligencia os laços e as comunicações do homem com seu meio.

Para a educação do futuro, é necessário promover grande remembramento dos conhecimentos oriundos das ciências naturais, a fim de situar a condição humana no mundo; dos conhecimentos derivados das ciências humanas, para colocar em evidência a multidimensionalidade e a complexidade humanas, bem como para integrar (na educação do futuro) a contribuição inestimável das humanidades, não somente a filosofia e a história, mas também a literatura, a poesia e as artes (Morin, 2011, pag. 44).

Para Morin, embora irremediavelmente façamos parte da natureza, a nossa cultura e a nossa mente, dotada de racionalismos, nos torna estranhos a este cosmos. Como afirma o autor: "o próprio fato de considerar racional e cientificamente o universo separa-nos dele" (Morin, 2011, pag. 47). E complementa afirmando sobre as formas de conhecimento que não dão conta de restabelecer a conexão homem-natureza:

A segunda [barbárie do século XX], gélida, anônima, vem do âmago da racionalidade, que só conhece o cálculo e ignora o indivíduo, seu corpo, seus sentimentos, sua alma, e que multiplica o poderio da morte e da servidão técnico-industriais (Morin, 2011, pag. 61). 
Neste trabalho não levantamos dados empíricos a respeito de abordagens didáticopedagógicas que têm sido vivenciadas no ensino de Educação Ambiental. Mas, com base nas discussões anteriores, defendemos a ideia de que se faz necessário acessar, durante as discussões sobre as questões ambientais, outras dimensões do ser humano, para que este venha a se reconectar com a natureza, se importe com ela. Só assim, ele estará finalmente motivado para, de fato, mobilizar sua força intelectual criativa, seus conhecimentos, e as tecnologias alternativas já disponíveis para suplantar a exploração predatória do homem capitalista exercida sobre a natureza.

Durante este trabalho demonstramos a presença significativa dos elementos da natureza enquanto componentes do repertório de significados presentes nos enunciados da obra de Luiz Gonzaga, discorremos sobre o quanto esses elementos impregnam as concepções de natureza e as formas como o homem nordestino sempre se relacionou com esta a fim de assegurar a sua sobrevivência.

Com base nesses resultados e nos referenciais teóricos aqui apresentados, acreditamos que a chave para a produção de novos sentidos de natureza capazes de reestabelecer vínculos significativos do homem com a natureza está no emprego de discursos/enunciados adequados, que sejam impregnados de elementos da natureza e que dialoguem com a realidade dos alunos.

De acordo com Berger e Luckmann (2007), os processos de interiorização dos significados dos elementos do convívio social em que estamos inseridos são veiculados na interação social dos indivíduos com sujeitos que lhes são referências significativas e com os quais se identificam. A partir desse ponto de vista, podemos sugerir serem os professores potenciais referências veiculadoras dos significados de natureza que devemos cultivar. Neste sentido, vale lembrar o que diz Sato: "a mediação pedagógica tem por obrigação revelar a subjetividade dos sujeitos" (Sato, 2001).

Assim, podemos propor a música como recurso didático-pedagógico, enquanto um conjunto de enunciados, fazendo-se estabelecer uma dialogicidade positivamente produtiva capaz de mobilizar as afetividades e emoções dos alunos em torno das questões ambientais, favorecendo a aquisição de significados e valores que tenham a ver com uma relação de equilíbrio entre homem e natureza. Ao discutir o papel das emoções e dos afetos no desenvolvimento do repertório linguístico segundo Wallon, Galvão afirma:

\footnotetext{
Por meio de jogos, danças e outros ritos, as pessoas realizam simultaneamente os mesmos gestos e atitudes, entregam-se aos mesmos ritmos. A vivência, por todos os membros do grupo, de um único movimento rítmico estabelece uma comunhão de sensibilidade, uma sintonia afetiva que mergulha todos na mesma emoção. Os indivíduos se fundem no grupo por suas disposições mais intimas, mais pessoais. Por esse mecanismo de contágio emocional estabelece-se uma comunhão imediata, um estado de coesão que independe de qualquer relação intelectual (Galvão, 2007, pag. 65).
}

Atendendo a necessidade de uma educação ambiental menos mecanicista, devemos nos propor métodos que promovam um processo ensino aprendizagem com ponto de partida nos saberes dos alunos e suas experiências de vida com a natureza, de modo que consigamos lhes conduzir ao desenvolvimento de seu próprio conhecimento e de uma autonomia que os liberte das exigências de um estilo de vida imposto pelo capital que é fortemente distanciador e predador 
da natureza. Significa lembrar que "ensinar não é transmitir conhecimento, mas criar as possibilidades para sua produção ou sua construção" (Freire, 2005, pag. 22).

Ainda, para Paulo Freire não se deve reduzir a formação ao puro treinamento técnico: “É por isso que transformar a experiência educativa em puro treinamento técnico é amesquinhar o que há de fundamentalmente humano no exercício educativo: o seu caráter formador. [...] Educar é substancialmente formar" (Freire, 2005, pag. 33). Corroborando com esta ideia Sato afirma: "ninguém pode dar consciência a alguém. Somos seres historicamente construídos, e capturamos a realidade na medida em que somos capazes de concebermo-nos nos nossos próprios mundos." (Sato, 2001).

Finalmente, propomos uma estratégia para o uso da música como recurso pedagógico em Educação Ambiental. Esta metodologia tem como objetivo a sensibilização para as questões ambientais a serem definidas. Assim, descrevemos o passo-a-passo da metodologia proposta:

Primeiro, se faz necessária uma sondagem a respeito das condições socioambientais dos alunos e sobre o seu repertório de conhecimentos e significados relativos à relação homemnatureza. De acordo com Paulo Freire, ensinar também exige respeito aos saberes prévios dos alunos. Para o autor, essa postura do professor é condição fundamental para que seja estabelecida intimidade entre os saberes curriculares e suas experiências sociais (FREIRE, 2005, pag. 30). Desse modo, estaremos acessando, segundo Vygotsky, a zona de desenvolvimento potencial, ou proximal, dos alunos, entendida como um ambiente mental composto de conhecimentos e habilidades em processo de maturação (Vigotsky; Luria; Leontiev, 2006, p. 112). A partir dos resultados dessa sondagem, o professor deverá selecionar o material didático e as estratégias metodológicas a serem utilizadas no decorrer da aula. Apenas um material que contenha elementos das vivências dos alunos e lhes apresente novos significados, sendo capazes de estimular uma relação mais saudável com a natureza, será adequado.

Num primeiro momento da aula, se fará a audição de músicas selecionadas numa atividade predominantemente lúdica. Esta atividade deverá contar com a participação ativa da turma, estimulando-se também a sua participação através do canto e da dança. As atividades lúdicas facilitam a aprendizagem, uma vez que mobilizam emoções e afetos (Galvão, p. 65).

Esse momento deverá ser seguido de uma análise pelos alunos dos enunciados verbomusicais e livre discussão dos significados interpretados por cada um. Estes enunciados verbomusicais consistem na obra selecionada, abrangendo música e letra, sendo "enunciado" aqui entendido conforme proposto por Bakhtin (Brait, 2014). Nesta oportunidade, serão inseridos os conceitos técnicos, porém sempre vinculados aos elementos e seus respectivos significados trazidos à tona durante a discussão.

Enfim, ao final da aula espera-se que a música possa ter ajudado os alunos a mobilizarem as suas afetividades em torno das questões ambientais e estejam, deste modo, mais propensos a produzirem significados novos de natureza e, a partir destes, consigam agir em prol de um meio ambiente ecologicamente equilibrado. 


\section{CONSIDERAÇÕES FINAIS}

A partir dos resultados obtidos e das discussões realizadas, concluímos que a obra de Luiz Gonzaga possui uma alta recorrência de elementos da natureza, com significados relevantes, contemplando as categorias fauna, flora, geologia/geomorfologia, fenômenos naturais e outros. Estes elementos aparecem significando desde meios de sobrevivência, fonte de deleite, indicadores de tempo-espaço, expressões da vontade divina e, às vezes, até atributos humanos.

Os significados que emergiram na análise dos enunciados são definidores da identidade do homem sertanejo retratado nas músicas cantadas por Luiz Gonzaga, o que é percebido pela coerência entre estes significados e atitudes e valores do sertanejo no contexto das relações sociais e na sua relação com a natureza.

Finalmente, o presente estudo revelou que a música é importante veículo de significados, podendo esta expressão artística ser proposta como recurso didático-pedagógico nos processos de formação em educação ambiental, configurando-se em uma via alternativa ao método de ensino tradicional, que parece insuficiente para garantir as motivações necessárias ao cuidado efetivo com a natureza.

\section{REFERÊNCIAS}

Bakhtin, M. (2006). Marxismo e filosofia da linguagem. São Paulo: Hucitec.

Berger, P. L., Luckmann, T. (2007). A construção social da realidade. Petrópolis: Editora Vozes.

Brait, B. (2014). Bakhtin: Conceitos-chave. 5a ed. São Paulo: Contexto. . (2006). Bakhtin: Outros conceitos-chave. 2a ed. São Paulo: Contexto.

Dreyfus, D. (2012). Vida do Viajante: a saga de Luiz Gonzaga. 3a ed. São Paulo: Editora 34.

Freire, P. (2005). Pedagogia da Autonomia: Saberes necessários à prática educativa. 31a ed. São Paulo: Paz e Terra S/A.

Galvão, I. (2007). Henri Wallon: uma concepção dialética do desenvolvimento infantil. 16a ed. Petrópolis: Editora Vozes.

Hall, S. (2006). A identidade cultural na pós-modernidade. 11a ed. Rio de Janeiro: Dp\&a.

Lane, S. T. M. (org.). (1994). Psicologia Social: o homem em movimento. 13a ed. São Paulo: Brasiliense.

Lima, G. F. C. (2004). Educação, emancipação e sustentabilidade: em defesa de uma pedagogia libertadora para a educação ambiental. Brasília: MMA.

Machado, G. B. (2013). História da Educação Ambiental no Brasil e no Mundo: Breve história da Educação Ambiental global. Disponível em: <http://www.portalresiduossolidos.com/historiada-educacao-ambiental-brasil-e-mundo/>. Acesso em: 09 jun. 2017.

Morin, E. (2011). Os sete saberes necessários à educação do futuro. 2a ed. São Paulo: 
Unesco/Cortez Editora.

Moscovici, S. (2005). Representações sociais: investigações em psicologia social. 3a Ed. Petrópolis: Vozes.

Pereira Neto, A. (2012). Gonzaga e "a triste partida" de Patativa do Assaré. Disponível em: <http://www.overmundo.com.br/banco/gonzaga-e-a-triste-partida-de-patativa-do-assare>. Acesso em: 23 jun. 2017.

Sato, M. (2001, maio). Debatendo os desafios da educação ambiental. Rev. Eletrônica Mestr. Educ. Ambient., Rio Grande, p.14-33.

Spink, M. J. (org.). (2004). Práticas discursivas e produção de sentidos no cotidiano: Aproximações teóricas e metodológicas. 3a ed. São Paulo: Cortez.

Vanderley, P. (2017) Letras. Disponível em: $<$ http://www.luizluagonzaga.mus.br/000/index.php?option=com_content\&task=category§ioni $d=4 \& i d=13 \&$ Itemid=103>. Acesso em: 09 jun. 2017.

Vigotski, L. S. (2007). A formação social da mente. 7a ed. São Paulo: Martins Fontes.

Vigotski, L. S., Luria, A. R., Leontiev, A. N. (2006). Linguagem, desenvolvimento e aprendizagem. 10a ed. São Paulo: Ícone.

Wallon, H. (2007). A evolução psicológica da criança. São Paulo: Martins Fontes. 